\title{
Юридический термин в правовом поле и за его пределами
}

\author{
Н. С. Громова \\ Уральский государственный экономический университет \\ ул. 8 Mapma, d.62, 620144, г. Екатеринбург, Россия. E-mail:gromovans@mail.ru
}

\begin{abstract}
В статье рассматриваются вопросы бытования юридических терминов в границах правового поля и за пределами языка права. Выявляется разница между терминами различных профессиональных сфер, устанавливается специфика терминологии общественных наук как средства редукции не только профессионального, но и социального знания. Юридический термин исследуется как один из видов специальных лексических средств, имеющих целый ряд дополнительных функций, актуализированных под воздействием специфики правоотношений. Устанавливаются особенности функциональной специфики юридического термина как на уровне синхронного взаимодействия субъектов правоотношений, что обеспечивает значимость регулятивной функции правовых терминов, производной от регулятивной и охранительной функций права, так и на уровне диахронного воздействия, когда актуализируется аксиологическая функция. Выявляются и анализируются особенности различных видов юридических терминов: общеупотребительных, специально-технических, специально-юридических. Также отмечается, что в условиях развития современного общества наблюдается широкое распространение юридических терминов благодаря включенности их в медиапространство за пределами правового поля, что часто не приводит к росту правосознания граждан и, наоборот, провоцирует (с учетом ложной мотивации в сознании носителей языка) смешение семантики общеупотребительных слов и терминов, модифицируя первичные смыслы в новом дискурсе. Дискурс, в котором оказываются общеупотребительные и специально-технические юридические термины, во многом подчиняет их своим законам и преображает в сознании носителей, трансформируя их вплоть до противоположного понимания. Использование юридических терминов за пределами правового поля должно быть подчинено логике их правового бытования, а не закономерностям функционирования нового дискурса.

Ключевые слова: термин, юридический термин, дискурс, язык права.
\end{abstract}

\section{Legal term in the legal environment and beyond}

\author{
N.S. Gromova \\ Ural State University of Economics \\ 8 Marta St.62, Ekaterinburg, Russia.E-mail:gromovans@mail.ru
}

\begin{abstract}
The article considers the existence of legal terms within the legal environment and outside the language of law. The difference between the terms of various professional spheres is revealed, the specificity of the terminology of the social sciences is established as a means of reducing not only professional, but also social knowledge. The legal term is studied as one of the types of special lexical means having a number of additional functions, foregrounded under the influence of the specifics of legal relations. The features of the functional specificity of the legal term are established both at the level of synchronous interaction of subjects of legal relations, which ensures the significa nce of the regulatory function of legal terms, derived from the regulatory and protective functions of law, and at the level of diachronous impact, when the axiological function is updated. The features of various types of legal terms are identified and analyzed: common, special technical, special legal. It is also noted that in the conditions of the development of modern society, legal terms are widely spread due to their incl usion in the media outside the legal environment. This often does not lead to an increase in the legal awareness of citizens and, on the contrary, provokes, given the false motivation in the minds of native speakers, the mixing of the semantics of common words and terms, modifying primary meanings in a new discourse. The discourse, in which there are commonly used and special technical legal terms, largely subordinates them to its laws and transforms them in the minds of speakers, leaving them the opposite understanding. The use of legal terms outside the legal environment should be subject to the logic of their legal existence not to the laws governing the functioning of the new discourse.

Key words: term, legal term, discourse, language of law.
\end{abstract}


Современные общественные отношения базируются на устойчивых нормах, которые формируют основы правоотношений, репрезентуясь посредством нормативно-правовых актов. С помощью таких актов устанавливаются, изменяются или отменяются нормы права, а следовательно, меняется правовое пространство. К подобным актам предъявляются жесткие требования как с содержательной, так и с формальной сторон. В связи с этим язык нормативно-правовых актов имеет свои особенности, а лексически е единицы, используемые для выражения воли правотворцев, реализуют комплексные - нормативно-стилистические задачи. С одной стороны, автор указывает на принадлежность предписаний к определенному стилю (официально-деловому), отнесенность описываемого факта, события, предмета и т. д. к особой сфере бытования (правовой), с другой же - формирует понятийный аппарат для дальнейшей правоприменительной деятельности, т. е. с конкретной практической целью, напрямую связанной с осуществлени ем функций государства. Так, слова, включенные в структуру НПА, приобретают особый статус- статус специальной терминологии.

Утверждение о значимости этихслов в рамках основной сферы их бытования не вызывает сомнений: прежде чем ввести термин в правовой оборот законодатель должен максимально обработать его, сформировать дефиницию и обеспечить адекватную корреляцию с другими элементами терминосистемы. Однако проблема бытования термина после его вхождения “в оборот» является весьма актуальной, т. к. зависит уже не только от воли законодателя, но и от общественных интересов и внешних факторов воздействия как на саму лексему, так и на правовые отношения в целом.

В данной работе представлена попытка выявить особенности юридическихтерминов как особой группы специальной лексики и исследовать особенности их трансформации за пределами правового контекста. С этой целью были проанализированы справочные (43 словаря, включая печатные и интернет-издания) и аналитические (более 100 научных работ различной направленности) матери алы, а также устойчивые контексты употребления юридических терминов в массовой коммуникации. В рамках эмпирической стороны рассмотрения вопроса был проведен ряд экспериментов, позволяющих выявить некоторые проблемы функционирования юридических терминов в среде обывателей. Таким образом, получилось структурировать информацию относительно содержания и места терминов в поле профессионального и общебытового языка и систематизировать взаимосвязи междуединицами языка права и иными лексемами.

Термин является частью специальной лексики, которая номинирует «предметы и понятия, относящиеся к различным сферам трудовой деятельности человека» [Розенталь 1976]. Однако в отличие от профессионализмов термин имеет официальный статус специальной единицы, фиксируется как часть специальной системы знаний и признается в качестве эталонной формы широким кругом носителей этих знаний. Если использовать характеристику Л. И. Рахмановой и В. Н. Суздальцевой [Рахманова 1997], то можно сказ ать, что все занятия субъекта, которые имеют необходимость вступать в юридические отношения с государством, обеспечиваются терминами, остальные - могут ограничиться профессионализмами. Юридические термины по структуре могут представлять собой как простые (однокомпонентные), так и сложные (многокомпонентные). Например, к однокомпонентным можно отнести такие, как экстремизм, конституция, правоотношение и др. К многокомпонентным соответственно - экстремистские материалы, конституционное право, абсолютное правоотношение, права и свободы человека и гражданина и т.д.

В словарных статьях Н. В. Васильевой, размещенных в словарях под редакцией В. Н. Ярцевой и Ю. Н. Караулова, пять особенностей термина указываются в качестве основных: 1) системность; 2) наличие дефиниции (для большинства); 3) тенденции к моносемичности в пределах своего терминологического поля; 4) отсутствие экспрессии; 5) стилистическая нейтральность. Соответствие всем этим качественным показателям и их перманентная ретранслируемость в процессе функционирования лексемы указыва ют на то, что перед нами термин. Юридические термины в силу специфики их функциональной сферы обладают всеми этими характеристиками. Если термин в процессе своего бытования утрачивает указанные признаки, то, как правило, он перестает быть и частью правового терминополя.

Термин является частью профессионального языка, в нашем случае, когда речь идет о юридических терминах, языка права. Язык нормативно-правовых актов, в частности, законов, чаще не определяют как специальный язык, а считают «разновидностью литературного языка», который «принадлежит к официально-деловому стилю» [Земляная 2010]. При этом многие ученые все пристальнее в последние годы обращают внимание на сферу юридической коммуникации и справедливо отмечают существование особого «юридического подъязыка», где "в наиболее концентрированном виде правовое знание содержится в системе словесных обозначений нормативно-правовых понятий, иными словами, в терминологии» [Барабаш 2015: 40].

Специфика юридического термина по отношению к другим видам специальной лексики может быть выявлена на различных уровнях в процессе анализа функций права. Так, на уровне синхронного взаимодействия субъектов правоотношений можно говорить об актуализации регулятивной функции правовых терминов, производной от регулятивной функции права, поскольку закрепление и упорядочивание общественных отношений невозможно без закрепления качественных характеристик этих отношений в терминологи и и ее упорядочения. Номинирование запрещенных вариантов поведения в юридических нормах способствует реализации и охранительной функции права. Можно говорить и об организационно-регламентирующей функции, т. к. без четкого терминологического разграничения задач и функций участников правоотношений, их прав и обязанностей невозможно фактически призвать их к ответственности. Также представлена предписывающая функция, поскольку невозможно инотолкование юридического термина: государственная воля выражается максимально конкретно, предписывая всем субъектам правоотношений определенные границы поведения и задавая эти границы для самого правоотношения во всех его модусах. Нормативно-правовой акт в этом смысле выступает как совокупность юридических терминов не как набор лингвистических единиц, а как список конкретных физических или эмоциональных правомерных или неправомерных действий. Рассматривая «экстремизм» как юридический термин, мы имеем дело не с нарицательным неодушевленным именем существительным мужского рода и 2-ого склонения, а с видом противоправной деятельности, предполагающей совершение определенных деяний, за которые предусмотрен конкретный вид отвественности. Слово при этом из разряда номинативной единицы переходит в нормативную. В работе Ю. Е. Костериной и Л. К. Кондратюковой термин как отдельная категория противопоставляется всем иным «ненормативным» средствам речи специалиста (профессионализмам, окказионализмам и др.) [Костерина 2014: 133], что представляется весьма оправданным, т. к. именно нормативный характер термина отличает его от всех остальных лексическихединиц в процессе профессионального общения «сведущихлиц».

На уровне диахронного влияния стоит отметить целый набор аксиологических функций, переводящих слово из нормативной единицы в ценностную. Парадокс состоит в том, что несмотря на нейтральную оценочность самого термина, являющуюся условием создания юридической дефиниции, он получает статус сентенции, т. к. с его помощью законодатель транслирует свое положительное или отрицательное мнение о факте действительности. При этом выражение этой оценки можно считать эксплицитным: автор в тексте закона прямо и открыто заявляет свою позицию в отношении конкретного юридического факта. Например, существует список отягчающихи смягчающих вину обстоятельств.

Таким образом, интерпретационная функция юридического термина бинарна: адресант (автор НПА) проводит свою

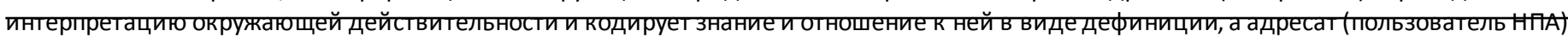


получает готовые знания и отношения, встраивает их в свою ценностную систему и уже на основе этого конструирует свое представление об окружающей действительности. Предписания, облаченные в языковую форму, помещаются в необходимый контекст, в зависимости от которого будут трактоваться всеми участниками правоотношений. Законодательное определение в процессе языковой обработки формирует саму «суть юридического понятия, устанавливаются потенциальные возможности и границы действий, связанных с реализацией юридических норм, обусловленных его (понятия) существованием» [Туранин 2006: 43]. Так, языковые единицы постепенно становятся юридическими маркерами. В работе «Язык и право» Т. В. Губаева пишет, что «ключевые слова в языке права - это всегда "сигналы", определяющие юридические мировоззрения, выражающие духовно-нравственные идеалы общества и моральные принципы, осознанные человеческим разумом и воспринятые данной правовой системой» [Губаева 2003: 17$18]$.

При этом нельзя не заметить, что статус разных терминов не одинаков. В рамках закрытых терминосистем, свойственных естественным или точным наукам, термин дольше сохраняет свою изоляцию от общеупотребительной лекси ки и сам статус термина. В отношении же общественных наук наблюдается иная тенденция: пропаганда знаний по социально значимым вопросам является обязательным условием повышения общего уровня развития населения и его гражданской активности, что приводит к ши рокому использованию терминологии как средства популяризации знаний с неизбежным нарушением границ между лексикой, являющейся частью закрытой системы, и общеупотребительной. Для юридической терминологии можно выделить и ряд специальных функций, которые не присущи терминологическим единицам иных профессиональных сфер, они во многом определяются спецификой бинарности отношений между общебытовым языком и юридической терминологией, поскольку первый представляет собой не толь ко базу формирования второй, но и выступает объектом ее применения. И, в связи с тем, что одной из важных функций термина является редукции знания, т. е. выражение концентрированного суждения об объекте, субъекте или их характеристиках, особенности содержательного наполнения каждой лексемы, ее дискурсивная привязка выходят на первый план. Знания сворачиваются в процессе создания термина, переходя от объемного развернутого повествования к краткой четкой формуле, в которой каждый структурный элемент представляется сложным и разложимым на иные простые элементы, т. к. аккумулирует большое количество информации разного рода: как специальной, так и социально детерминированной. Если мы говорим о терминах общественных наук, то объем второго рода информационного наполнения становится во многом определяющим. В частности, юридический термин создается не только для нужд государства, но и для нужд каждого человека, а следовательно, каждый так или иначе сталкивается с этой лексик ой и она не может быть отделена от социума. К юридической терминологии обращаются не только специалисты, но и обычные граждане, не имеющие специальных знаний по вопросам интерпретации содержания термина и руководствующиеся собственными представлениями о его характеристиках на базе уровня владения русским литературным языком. Дело в том, что юридическая терминосистема представляется частью лексикона практически любого лица, поскольку обращена к социально значимым сторонам жизни человека, с которыми он постоянно сталкивается в быту, в профессиональной деятельности, при межличностном и межгрупповом взаимодействии.

Создание правовых норм является важной частью регулирования общественных процессов, поэтому с включением в текст правового акта языковой единицы она перестает быть частью только лингвистического пространства и приобретает статус нормативной дефиниции, определяющей специфику дальнейшего бытования формируемого термина. При этом сфера бытования определяет и особое внимание к качественным показателям термина. Если один лингвист будет использовать одну терминологию для обозначения языковых явлений, а другой - иную, то это не нанесет ущерба обществу в целом. Но в случае таких терминологических разногласий между судьями, когда в разных судах одни и те же преступления будут именоваться по-разному или одно правонарушение будет квалифицироваться как разные виды действий, правовая система не будет работоспособной, а следовательно, пострадает общество. Именно поэтому единообразие и кодифицированность юридической лексики обеспечивают реализацию ее нормативности и, как следствие, нормотворческой функции. Хотя, конечно, нельзя не заметить, что на практике наблюдается и целый ряд отклонений от указанных правил.

Так, в диссертационном исследовании Н. Ю. Мартышко, анализируя состояние современной юридической терминологии и законодательного дискурса в целом, выявляет из 265 единиц 34 \% потенциально манипулятивных формулировок, направленных на введение в заблуждение правоприменителя. Автор обращает внимание на существование "тупиковых формулировок», которые близки к манипулятивным терминам, но по сути не являются ими, т. к. вместо расшифровки содержания единицы уводят правоприменителя к другим правовым актам, в которых тоже нет детализации содержания [Мартышко 2015].

Есть и другая проблема, на которой акцентирует внимание В. М. Лейчик, когда с помощью термина можно сознательно дезинформировать оппонентов, т. е. использовать ложномотивированный вариант (например, социальное партнерство вместо наемный труд). При этом такой выбор может быть следствием как неумелого использования специальной лексики или ошибочной семантизации, так и продуманной манипулятивной стратегии. Или, как отмечает Д. Милославская, нечеткое разграничение многозначности в терминологическом поле включает две группы: «примеры "сознательного введения в заблуждение читателя" и примеры "бескорыстной небрежности"»[Милославская 1999].

Особенностью многих юридических терминов на данный момент является их размытый характер. Изначально можно предположить, что хотя бы ключевые термины с учетом построения структуры НПА должны иметь разъяснение в дефиниционной части содержания акта, однако это не всегда реализуется на практике.

Обратимся к анализу Федерального закона «О противодействии экстремистской деятельности». Данный акт является отраслевым и теоретически должен содержать обширную дефиниционную часть либо с постатейным разъяснением, либо в виде группы терминов в начале акта. В данной ситуации не применяется принцип постатейной трактовки терминов (как, например, в УК РФ), поэтому в акте имеется серия дефиниций в начале документа, что в последние годы становится более ретранслируемой формулой в тексте законов (например, ст. 2 Ф3 "Об охране здоровья граждан от воздействия окружающего табачного дыма и последствий потребления табака» или ст. 3 ФЗ "О противодействии терроризму"). Однако к основным понятиям в анализируемом акте отнесено только 4, именно их законодатель определяет в качестве нормативных и дает им определения: экстремистская деятельность (экстремизм), экстремистская организация, экстремистские материалы, символика экстремистской организации. При этом первый и основной термин, от понимания которого зависит интерпретация самого вида деятельности, имеет довольно расплывчатый характер и противоречит основным требованиям к построению терминологической дефиниции - фиксированный смысл отсутствует, что порождает множественность трактовок и свободу интерпретации самого явления, более или менее ясным становится пространный список проявлений этой деятельности, включающий 257 слов.

В данном случае мы имеем дело с дефиницией-перечнем, иначе называемой «казуальным перечнем», которые «в строго логическом смысле ... определениями не являются - они просто используются вместо определений, так как в той или иной степени 
раскрывают содержание нормативного понятия» [Леоненко 2015]. В отличие от классических дефиниций (полных или неполных), где присутствует комплекс родовых или только ряд видовых признаков, но все же представлен набор этих признаков, данная дефиниция является простым способом характеристики, т. к. содержит перечень деяний, относимых к рассматриваемой категории правонарушений. Во многом такой принцип трактовки связан с недостаточной разработанностью термина и отсутствием вследствие этого обоснованной возможности его толкования через выделение признаков. Иллюстративность такой дефиниции приводит к громоздкости структуры и сужению границ термина до пределов указанных форм поведения, в этом случае каждая новая форма поведения будет считаться правовой вплоть до включения ее непосредственно в текст закона и исключения, тем самым, из группы нормативного поведения. Именно это, на наш взгляд, в дальнейшем становится причиной семантических модификаций термина при смене дискурса.

Такая ситуация во многом связана не столько с волей законодателя, сколько с особенностями самого термина. Принято делить юридические термины на три разновидности [Юридический энциклопедический словарь 2016]: общеупотребительные, отражающие область неспециальных знаний (например, закон, договор, гражданин); специально-технические, отражающие область специальных знаний, необходимых для организации как профессиональной, так и непрофессиональной коммуникации в пределах одной сферы (образование, здравоохранение, сельское хозяйство); специально-юридические, отражающие область узкоспециальных знаний и обладающие особым правовым содержанием в процессе профессиональной коммуникации (например, объективное вменение, принцип вины, рецидив преступлений).

В результате содержательного анализа и ряда лингвистических экспериментов можем заметить, что третья группа терминов, очевидно, в силу их ограниченного употребления за пределами юридического дискурса, редко подвергается трансформациям в нов ом лексическом окружении: неспециалист либо знаком со словом в исконном значении, либо не знаком и не стремится его идентифицировать и трансформировать. В связи с этим данная группа терминов чаще всего даже при смене дискурса сохраняет свое исходное юридическое значение, однако стоит отметить, что такие слова редко покидают свой привычный «ареал обитания» и долгое время идентифицируются носителями языка как специализированная лексика. При этом могут быть и исключения. Так, достаточно специализированный термин декриминализация стал практически общеупотребительным в связи с изменениями в антиэкстремистском законодательстве, инициированными Президентом РФ и широко обсуждаемыми в кругах не-юристов в силу общественной актуальности вопроса. Первые же две группы часто выступают материалом для формирования новых значений за пределами терминосистемы, которые могут иметь различный статус.

Выходя за границы своего «ареала обитания», термин приобретает новые связи за пределами терминосистемы и самого первичного дискурса, что влияет на его содержание, а также теряет и дискурсивную привязку, обеспечивающую ему нормативный статус. С потерей своего особого статуса юридический термин лишается и своего ключевого признака - правовой предзаданности содержания, теперь каждый может конструировать его под себя, с учетом собственного мировосприятия. Этот факт может иметь два последствия: потеря словом статуса термина при условии разрыва связи стерминосистемой (например, слова кляуза, каторга, кабала не имеют на данный момент актуального юридического значения, зато сохранились в общеупотребительной речи в качестве эмоциональной окрашенных лексем) либо, при сохранении этой связи, одновременное бытование в разных дискурсах с различным семантическим наполнением. Например, можно обратиться к категории слов, которые рассматриваются в исследовании Н. Г. Сичинавы - законный и преступный. Первое в юридической терминологии представлено в значении «соответствующий закону, основанный на законе», «юридически оформленный», а в общеупотребительной речи - «справедливый, правильный, обоснованный». Второе имеет аналогичные коннотации: в праве характеризуется как «являющийся преступлением, содержащий в себе преступление», а в общем употреблении - «непозволительный, заслуживающий осуждения» [Сичинава 2012].

Одновременно с этим происходит согласование правовых и наивных обывательских представлений о значении правовых терминов. Дефиниция в этом случае выступает звеном в познавательной цепочке, и имеет значение процесс перевода характеристик должного поведения из юридического дискурса (в значении - правовое) в обывательский дискурс (в значении - правильное). Правовое определение при этом можно рассматривать в качестве маркера, определяющего процесс интерпретации явлений окружающего объективного мира. А следовательно, оценка зависит не от его объективных характеристик, а от отношения субъекта к самой сфере изначального бытования термина. Так, многие юридические термины, будучи изначально нейтральными, переосмысляются носителями языка как оценочно маркированные в силу, например, идеологической позиции. Например, слова либерал, националист имеют в сознании носителей различных политических групп совершенно противоположную оценку: от одобрительно положительной до резко отрицательной. Следовательно, первой тенденцией, о которой можно говорить в отношении трансформации юридического термина в связи со сменой дискурса, является прямая зависимость значения лексемы от правовой позиции субъекта, когда в качестве имеющих оценочную окраску выступают, казалось бы, совершенно нейтральные в литературном языке единицы.

Второе направление, определяющее часть проблем с применением и интерпретацией юридической терминологии, связано с выбором из естественного языка мотивирующей лексемы при конструировании термина. Проблему представляют лексемы, имеющие изначально затемненное значение либо смежное или полисемичное с иными лексемами. Например, как показывают результаты опросов, проведенных автором в образовательных учреждениях г. Екатеринбурга среди студентов, сложность представляет проведение границ между такими единицами, как символика и атрибутика, пропаганда и агитация, или необходимость сформулировать четкую категорию гласности, сочиальной группы, публичного демонстрирования и пр.

Третьей тенденцией является процесс переосмысления термина под влиянием актуализации отдельных реалий в сознании носителей языка различных возрастных групп. Так, по результатам опросов, проводимых автором в образовательных учреждениях г. Екатеринбурга и Свердловской области среди студентов с 2014 года по настоящий момент, серьезную сложность представляет интерпретация термина экстремизм: значительная часть опрашиваемых не видит разницы между экстремистами и экстремалами. При этом, если в 2014-15 гг. процент лиц, которые давали ложную интерпретацию, был ниже 10\% от общего количества опрашиваемых, то в 2018-19 гг. он стремительно растет, достигая в отдельных образовательных группах до 50\% респондентов, включая и студентовюристов первых курсов.

Таким образом, можем отметить, что юридическийтермин, имея особый статус в силу реализации нормативной функци и, тем не менее, активно вступает во взаимоотношения с лексическими единицами за пределами терминосистемы. Границы лексического правового поля становятся все более проницаемыми с развитием институтов гражданского общества и ростом правосознания. Интерес населения к вопросам правового значения свидетельствует о необходимости разгерметизации юридической терминосистемы. Однак о нельзя не отметить, что в условиях развития современного общества широкое распространение юридических терминов благодаря включенности их в медиапространство часто не приводит к росту правосознания граждан и, наоборот, провоцирует с учетом ложной

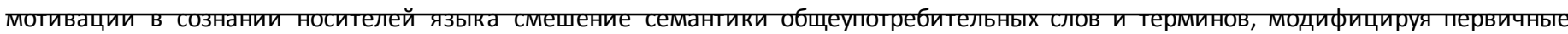


смыслы в новом дискурсе. Дискурс, в котором оказываются общеупотребительные и специально-технические юридические термины, во многом подчиняет их своим законам и преображает в сознании носителей, трансформируя их вплоть до противоположного понимания. В силу затемненности внутренней формы для обывателя, не знакомого с исконной семантикой, значение термина выводится им по аналогии, что приводит к смешению паронимов, неправильной актуализации полисемии и пр. Ввиду этого хочется отметить, что использование юридических терминов за пределами правового поля должно быть подчинено логике их правового бытования, а не закономерностям функционирования нового дискурса.

\section{Литература}

1. Барабаш О. В. Разграничение омонимии и полисемии юридических терминов / Вестник Московского государственного гуманитарного университета им. М.А. Шолохова. 2015. № 2. С. 39-49.

2. Губаева Т. В. Язык и право. М., 2003.

3. Земляная Т. Б., Павлычева О. Н. Использование терминологии в правотворчестве / Журнал научно-педагогической информации. 2010. № 10. URL: http://www.paedagogia.ru/2010/47-10/110-zemlyanayapavlicheva.

4. Костерина Ю. Е., Кондратюкова Л. К. Критерии и принципы отбора терминов / Омский научный вестник. 2014. № 1 (125) С. 133 137.

5. Леоненко Н. Т. Законодательная техника. Новосибирск, 2015.

6. Мартышко Н. Ю. Смысловая модификация терминов в современном законодательном дискурсе: диссертация ... кандидата филологических наук: 10.02.19. Волгоград, 2015.

7. Милославская Д. Юридические термины и ихинтерпретация / РЭГ. № 21 [27]. 1999.

8. Рахманова Л. И., Суздальцева В. Н. Современный русский язык. Лексика. Фразеология. Морфология. М., 1997.

9. Сичинава Н. Г. Переносное употребление юридических терминов в общелитературном языке / Язык и право: актуальные проблемы взаимодействия. 2012.

10. Словарь-справочник лингвистических терминов / Д. Э. Розенталь, М. А.Теленкова. Изд. 2-е. М.,1976.

11. Туранин В.Ю. Сущность и значение дефиниции в современном законодательном тексте / Современное право. 2006. № 5. С. $43-48$.

12. ридический энциклопедический словарь / под ред. А. В. Малько. 2-е изд. Москва, 2016.

\section{References}

1. Barabash, O. V. (2015). Differentiation of homonymy and polysemy of legal terms [Razgranicheniye omonimii i polisemii yuridicheskikh terminov]. Bulletin of Moscow State University for the Humanities M.A. Sholokhov, 2, 39-49 (in Russian).

2. Dictionary of linguistic terms [Slovar'-spravochnik lingvisticheskikh terminov] (1976). D. E. Rosenthal, M. A. Telenkova (Eds.). Moscow (in Russian).

3. Gubaeva, T.V. (2003). Language and law [Yazyki pravo]. Moscow (in Russian).

4. Kosterina, Yu. E., Kondratyukova, L.K. (2014). Criteria and principles for the selection of terms [Kriterii i printsipy otbora terminov]. Omsk Scientific Bulletin, 1(125), 133-137. (in Russian).

5. Legal Encyclopedic Dictionary [Yuridicheskiy entsiklopedicheskiy slovar'] (2016). A.V. Malko (Ed.). Moscow (in Russian).

6. Leonenko, N. T. (2015). Legislative technique [Zakonodatel'naya tekhnika]. Novosibirsk (in Russian).

7. Martishko, N. Yu. (2015). Semantic modification of terms in the modern legislative discourse. Thesis of Doctoral Dissertation. [Smyslovaya modifikatsiya terminov v sovremennom zakonodatel'nom diskurse]. Volgograd (in Russian).

8. Miloslavskaya, D. (1999). Legal terms and their interpretation [Yuridicheskiye terminy i ikh interpretatsiya]. REG, 21(27) (in Russian).

9. Rakhmanova, L.I., Suzdaltseva, V.N. (1997). Modern Russian language. Vocabulary. Phraseology. Morphology. [Sovremennyy russkiy yazyk. Leksika. Frazeologiya. Morfologiya]. Moscow (in Russian).

10. Sichinava, N. G. (2012). The portable use of legal terms in the general literary language [Perenosnoye upotrebleniye yuridicheskikh terminov v obshcheliteraturnom yazyke]. Language and Law: Actual Problems of Interaction (in Russian).

11. Turanin, V.Yu. (2006). The essence and meaning of the definition in the modern legislative text [Sushchnost' $i$ znacheniye definitsii $v$ sovremennom zakonodatel'nom tekste]. Modern Law, 5, 43-48 (in Russian).

12. Zemlyanaya, T. B., Pavlycheva, O. N. (2010). Use of terminology in law-making [Ispol'zovaniye terminologii v pravotvorchestve]. Journal of scientific and pedagogical information, 10. Available from: http://www.paedagogia.ru/2010/47-10/110-zemlyanayapavlicheva (in Russian).

\section{Citation:}

Громова Н.С. Юридический термин в правовом поле и за его пределами. // Юрислингвистика. - 2019. -13. - С. 5-9.

Gromova, N.S. (2019). Legal term in the legal environment and beyond. Legal Linguistics, 13, 5-9.

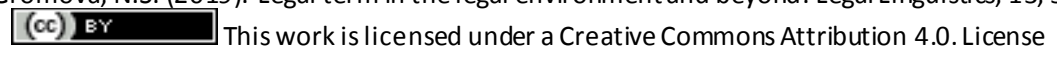

